\title{
ВОЕННО-ПОЛИТИЧЕСКОЕ ВЛИЯНИЕ США И ЗАПАДНОЙ ЕВРОПЫ В ВОСТОЧНО-ЕВРОПЕЙСКОМ РЕГИОНЕ
}

\author{
М.Ю. Пеньков \\ Институт международных отношений и социально-политических наук \\ Московского государственного лингвистического университета \\ ул. Остоженка, 38, 119034, Россия, Москва
}

\begin{abstract}
Предметом исследования статьи является военная политика США и стран Западной Европы в Восточно-Европейском регионе. В статье показана нацеленность США и стран Западной Европы на закрепление и расширение своего влияния в Восточно-Европейском регионе и создание на постсоветском пространстве «санитарного кордона» вокруг России. Особое внимание уделяется анализу стремлений Запада использовать страны Восточной Европы для создания зон нестабильности в государствах, приграничных с Россией, и процессам евроатлантической интеграции стран Восточной Европы. Основным выводом проведенного исследования является то, что США и страны Западной Европы используют все возможные, в том числе и явно противоречащие международному праву, методы (наглядным примером является Украина) для вовлечения стран Восточной Европы и в особенности бывших республик СССР в орбиту своего влияния. При этом в угоду своим интересам они готовы принимать сугубо политические решения об интеграции в евроатлантические структуры даже тех стран, которые не соответствуют установленным на Западе критериям.
\end{abstract}

Ключевые слова: международная политика, транснациональная политика, демократические институты, интеграция восточноевропейских стран, внешняя политика, европейское влияние США, восточно-европейский регион, коалиционная политика, европейская геополитическая архитектура, мировая политика

В последние годы США и Западная Европа все больше активизируют деятельность, направленную на вовлечение в орбиту своего влияния бывших республик Советского Союза, в первую очередь в Восточной Европе (См.: $[1 ; 4 ; 8 ; 14])$. Тем самым США не оставляют попыток дальнейшего продвижения НАТО к границам России, образования вокруг нее кольца из враждебных государств и создания зоны перманентной политической нестабильности на российских границах (См: $[3 ; 23])$.

В настоящее время внешнеполитические усилия России в Европе направлены на то, чтобы предотвратить свою изоляцию от складывающейся новой европейской архитектуры (См.: [5; 19]). Продолжающееся расширение на восток Североатлантического союза - лишь одна, хотя и наиболее заметная из сторон такого неблагоприятного развития событий.

В ситуации, когда большинство старых рычагов внешнеполитического влияния России перестало действовать, а новые приобрести пока не удалось, практически нет такого аспекта в европейском развитии, который не мог бы при определенных условиях работать на ослабление российских позиций в Европе (См.: 
$[16 ; 18])$. Это касается и интеграционного строительства, и субрегионального сотрудничества, и амбиций отдельных держав (См.: [7; 10; 21]). У России нет серьезных механизмов, способных предотвратить дезинтеграцию постсоветского пространства и включение его по частям в чужие сферы влияния. В наиболее концентрированном виде геополитический тупик, в котором оказалась Россия, проявился в Восточной Европе. В этом регионе блок НАТО, хотя формально больше и не противник России, но так и не переставший восприниматься ею как угроза, может взять под свое крыло еще почти 50 млн человек и вплотную подойти к рубежам, которые всегда были для России наиболее уязвимыми.

\section{РЕНЕССАНС ВНЕШНЕЙ ТРАНСАТЛАНТИЧЕСКОЙ ПОЛИТИКИ США}

Может ли Россия противопоставить что-либо западной экспансии на восток и предотвратить формирование там «санитарного кордона», который при неблагоприятных условиях может захватить многие республики бывшего СССР и даже поставить под вопрос ее позиции в собственных западных регионах (Калининградская область)? Прежде чем искать ответ на этот вопрос, следует разобраться в том, какие рычаги влияния на Восточную Европу в политических вопросах и в сфере безопасности использует сам Запад, каково здесь «разделение труда» между США и Западной Европой, насколько велико соперничество между ними в регионе.

Для США отношения со странами Восточной Европы являются не столько самоценными, сколько стратегически значимыми в контексте отношений с западноевропейскими союзниками, а также с Россией и странами СНГ. В настоящее время происходит их существенная переоценка с учетом изменившихся мировых реалий и опыта включения этих стран в трансатлантические и европейские структуры (См.: [2; 15]).

Как известно, США выступали главным двигателем стратегии расширения НАТО и Евросоюза и включения в эти структуры стран Восточной Европы. Этот процесс первоначально протекал достаточно быстро, что, по мнению влиятельных американских аналитиков, стало возможным, во-первых, благодаря выработке общей стратегии Запада в отношении стран региона; во-вторых, благодаря настойчивости самих стран и их способности играть на чувстве «морального долга» западных стран перед ними, и, наконец, в-третьих, благодаря слабости России, неспособной в тот момент противодействовать этому процессу.

Однако в настоящее время положение в мире изменилось. Прежде всего, изменился сам Запад: приход к власти Д. Трампа вызвал негативную реакцию со стороны западных партнеров, его заявления о нежелании в одиночку нести финансовую нагрузку в НАТО и необходимости сближения с Россией усилили трансатлантические разногласия и нанесли заметный урон сплоченности этого сообщества (См.: [9; 20]).

Изменился и восток Европы. Прежнюю стратегию, апробированную в центрально-европейском регионе, еще можно применить на западе Балканского полуострова, но никак не в странах СНГ, которые включают в себя Восточную Европу и Закавказье (речь идет о дуге, граничащей с Евросоюзом, Россией и регионом Ближнего Востока). 
Эти страны менее однородны, и у европейцев по отношению к ним нет ни «исторического морального долга», ни стимула «вернуть их в Европу», а потому испытанные инструменты там малоэффективны. Стратегия 90-х гг. XX в. заключалась в двойном расширении НАТО и Евросоюза при укреплении трансатлантических связей после окончания «холодной войны» и краха двухполярной системы (См.: [17; 22]).

Наконец, изменилась и Россия, активизировалась политика нашей страны на европейском континенте в целом, включая регион Восточной Европы. Отношения с Россией всегда были предметом дискуссий между Вашингтоном и его ключевыми европейскими союзниками. А в последние годы в связи с укреплением России, все более настойчиво отстаивающей свои внешнеполитические интересы, в том числе и в отношениях с соседними государствами, сложившийся в 90-е гг. прошлого и в начале нынешнего века, консенсус западных стран заметно ослаб [11].

Вследствие этого США столкнулись с необходимостью скорректировать свой внешнеполитический курс. При этом главным приоритетом бесспорно являются преодоление кризиса и экономическое оживление Америки. В связи с этим большую роль в своих внешних связях Вашингтон стал отводить и Китаю.

Безусловно, важным остается для США и решение проблем в Сирии, Ираке, Иране, Афганистане и Пакистане. Концепция «AfPak» подразумевает региональный подход. Основные угрозы безопасности - международный терроризм и распространение оружия массового уничтожения — исходят из Азии (Ближний Восток, Центральная и Западная Азия, Тихоокеанский регион). Таким образом, вектор внешнеполитической активности США смещается в Азию, и Европа теряет для США прежнее геостратегическое значение. При этом, несмотря на имеющиеся серьезные разногласия, в вопросах стратегической стабильности и в решении региональных проблем важным партнером для Вашингтона становится Москва.

В настоящее время в сфере внешней политики перед США стоит задача возродить американское лидерство и американскую мощь. Для этого, активно используя дипломатию и «мягкую» силу, Вашингтон стремится примирить и консолидировать европейских союзников для выработки совместной стратегии Запада. По сути, речь идет о ренессансе трансатлантических отношений начала 90-х гг. прошлого века, но на новой основе.

\section{РОССИЯ, США, НАТО И ЕВРОСОЮЗ - ПОИСК ВОСТОЧНО-ЕВРОПЕЙСКИХ КОМПРОМИССОВ}

В США полагают, что, столкнувшись с консолидированным Западом, Россия сама начнет активнее искать точки соприкосновения и идти на уступки.

Большинство западных экспертов достаточно низко оценивают шанс найти долгосрочный и стабильный компромисс в отношениях между Россией и западными партнерами - США, НАТО и Евросоюзом. Заявленные Россией позиции признать пространство СНГ зоной особых российских интересов и включить ее в европейские механизмы принятия решений (проект Договора о европейской безопасности) - вызывают неоднозначную реакцию на Западе. 
События вокруг Южной Осетии показали способность России противостоять «жесткой» силе, однако, как полагают на Западе, она более уязвима при активном политическом давлении с использованием элементов «мягкой» силы (что достаточно спорно судя по российской реакции на украинский кризис, приведшей к возвращению Крыма) (См.: [6; 12]). Ставка делается на то, чтобы, поощряя Россию открыться западному миру, влиять на нее в выгодном для Запада ключе.

Таким образом, в условиях определенного дефицита ресурсов для проведения активной внешней политики и учитывая серьезные негативные последствия глобального экономического кризиса, США пытаются возглавить многосторонние усилия и укрепить ослабевшее единство западного сообщества. Особый упор сделан на укрепление сотрудничества со старыми союзниками в Европе, прежде всего с Великобританией, Германией и Францией. При этом речь идет об изменении скорее стиля внешней политики, чем ее сущности и целей.

Демонстрация тесных и особых союзнических отношений со странами Центральной и Восточной Европы, как это было ранее иногда в ущерб отношениям с Западной Европой, приходит в определенное противоречие с целями США по сплочению трансатлантического сообщества. Новые подходы Вашингтона требуют некоторой корректировки отношений с союзниками в Восточной Европе.

В целом, рычаги влияния Запада на эволюцию в Восточной Европе нередко воспринимаются прямолинейно. На самом деле непосредственное западное влияние распространяется на довольно ограниченный круг факторов, которые помимо определения самых общих принципов экономических преобразований включают внешнеполитические и военно-политические аспекты. Что же касается внутреннего развития Восточной Европы и России, то США и Европейский Союз не могут прямо влиять на политическую жизнь в этих странах [27]. Хотя в Восточной Европе поведение политических элит более-менее предсказуемо, страны этого региона также еще долго будут оставаться весьма далекими по своей политической культуре от традиционного Запада.

Определенные универсальные критерии, выдвигаемые для допуска этих стран в западные институты, касаются главным образом внутренних факторов развития - стабильности и необратимости рыночных институтов, демократического развития. Между тем именно соответствие этим критериям труднее всего проверить, и именно здесь наиболее велик соблазн незрелых посткоммунистических элит лишь имитировать демократические процессы и институты.

Прогрессирующий национализм и явные проявления авторитаризма стали визитной карточкой многих восточноевропейских государств, позиционирующих себя как демократические. Наличие в этих странах отдельных признаков демократии не является показателем их перехода на демократический путь развития.

Между тем все эти страны претендуют на интеграцию в европейские и атлантические структуры, хотя далеко не очевидно, что Западу в таких условиях удастся сохранить притягательность своих демократических ценностей и устоять перед натиском «полудемократической» культуры с востока.

На Западе признается, что молодые демократии должны получать экономическую помощь, необходимую для поддержания стабильности и заключающуюся 
в предоставлении займов, отсрочек по погашению долгов, торговых преференций от западных правительств и международных финансово-экономических институтов, разумеется, при условии, что эти страны будут соблюдать демократические нормы (правда, у частных инвесторов порой действует другой критерий - приоритет стабильности). Теоретически такой подход должен способствовать преодолению «тоталитарного наследия». В качестве положительных примеров часто приводится быстрый переход к демократии в Испании и Португалии, которым сопровождался их путь в Европейское сообщество (а Испании, кроме того, и в НАТО).

Однако представляется, что эти примеры отнюдь не универсальны, и в некотором роде даже единичны. Когда речь шла о демократизации этих двух стран, Европа и вообще все западное сообщество были едины в том, чтобы добиться их скорейшей интеграции в это сообщество в качестве его органичной части и не дать влиятельным в то время коммунистам установить над ними контроль. Однако уже случай с Турцией, стремящейся вступить в Европейский Союз и при этом неспособной, несмотря на все давление европейских институтов, обеспечить прогресс в соблюдении прав национальных меньшинств, прекратить оккупацию части Кипра, демонстрирует ограниченность влияния Запада на внутреннее развитие и даже внешнюю политику тех стран, которые хотят присоединиться к западному сообществу (См.: [12; 25; 26]).

Нет необходимости доказывать, что интеграция восточноевропейских стран в западные структуры будет лишь множить число подобных случаев. Конечно, само вовлечение бывших коммунистических стран в западную орбиту все равно остается определенной гарантией против возрождения тоталитаризма. Однако за период, прошедший после восточноевропейских революций, сам Запад, похоже, отнюдь не стал усиливать акцент на таких ценностях, как демократия и права человека, уважение к которым далеко не одинаково в разных странах Восточной Европы. Ведь проверять каждую из стран региона на совершенство демократических институтов и политической культуры фактически означало бы риск упустить их. Североатлантический альянс, принимающий в свои ряды Черногорию, демонстрирует, что эти ценности часто трактуются исходя из стратегической значимости той или иной страны для Запада.

Приоритет демократии не всегда стыкуется для Запада с другой важнейшей целью - заполнением стратегического вакуума и вовлечением этих стран в орбиту своего военно-политического доминирования. НАТО - удобный механизм, позволяющий государствам Восточной Европы сократить путь на Запад, ведь через Евросоюз с его часто трудновыполнимыми требованиями к экономической эффективности и внутриполитическому устройству такой путь будет гораздо сложнее. Вовлекая эти государства в свою орбиту в первую очередь через натовские механизмы, США и их союзники смогут, если потребуется, закрывать глаза на некоторые несоответствия их внутреннего устройства критериям, принятым на Западе. Ведь Португалию и Грецию даже в период авторитарных диктатур никто не думал исключать из НАТО, в то время как для приема в Европейское сообщество характер их режимов был серьезнейшим препятствием. 


\section{ЗАКЛЮЧЕНИЕ}

Таким образом, США и страны Западной Европы используют все возможные, в том числе и явно противоречащие международному праву, методы (наглядным примером является Украина) для вовлечения стран Восточной Европы и, в особенности, бывших республик СССР в орбиту своего влияния. При этом в угоду своим интересам они готовы принимать сугубо политические решения об интеграции в евроатлантические структуры даже тех стран, которые не соответствуют установленным на Западе критериям.

\section{БИБЛИОГРАФИЧЕСКИЙ СПИСОК}

[1] Антология. Расширение Евросоюза за счет стран Центрально-Восточной и Юго-Восточной Европы. Ошибки реализации или банкротство концепции. РИСИ, 2014.

[2] Артеменко C.В., Федорова И.Л. Европейская региональная геополитика как элемент развития трансграничных территорий // Проблемы безопасности российского общества. 2014. № 1 .

[3] Байректоревич A. Восточная Европа - мир последних отстающих // Право и политика. 2015. № 4.

[4] Гейти Ч. Шаг назад в Центральной и Восточной Европе // The Quarterly Journal. 2007. T. VI. № 3.

[5] Гиниятов Ф.М. Политические и экономические аспекты присоединения стран Центральной и Восточной Европы к Европейскому союзу // Вестник экономики, права и социологии. 2014. № 2.

[6] Фролова О.А. Анализ внешнеполитических документов администрации Дж. Буша-младшего и Б. Обамы как основополагающих стратегических доктрин политики США на мировой арене // Вестник Российского университета дружбы народов. Серия: Политология. 2015. № 4.

[7] Калан Д., Дерлик М. «Хромые тигры» Восточной Европы: неортодоксальная экономическая политика в Венгрии против мер жесткой экономии в Румынии // Мир перемен. 2016. № 1.

[8] Кобринская И.Я. Политика США в центральной и восточной Европе // США-Канада: экономика, политика, культура. 2000. № 2.

[9] Кукушкин Ю.А., Богомолов А.В., Ушаков И.Б. Математическое обеспечение оценивания состояния материальных систем // Информационные технологии. 2004. № 7 (приложение). 32 c.

[10] Латкина В.A. Восточный вектор европейской политики соседства: ловушки европеизации // Вестник МГИМО Университета. 2014. № 6 (39).

[11] Маслов Ю.К. Роль гражданского общества в формировании новой системы власти в странах Центральной и Восточной Европы // Науковий вісник Одеського національного економічного університету. 2014. № 7 (215).

[12] Приймачук Д.В. Центральная Азия и Соединенные Штаты Америки: проблемы и перспективы // Международные отношения. 2017. № 1.

[13] Орлик И.И. Дифференциация Центрально-Восточной Европы и отношения с Россией. М.: Институт экономики РАН, 2015. 50 с.

[14] Орлик-Гарлик И.И. Центрально-Восточная Европа в современной геополитике // Мир перемен. 2015. № 4.

[15] Амиантова И.С. Международные санкции как способ решения политических проблем // Вопросы национальных и федеративных отношений. 2017. № 1 (36).

[16] Путинцев И.С. Варианты распределения полномочий в странах Центрально-Восточной Европы // Международные процессы. 2015. Т. № 41. 
[17] Курылев К.П., Нарышкин В.С., Озинковская Е., Рахимов К.Х. Евразийский экономический союз во внешнеполитической стратегии России // Вестник Российского университета дружбы народов. Серия: Международные отношения. 2016. Т. 16. № 1.

[18] Абашидзе А.Х., Ильяшевич М.В. О защите национальной идентичности в глобализирующемся мире // Научно-аналитический журнал Обозреватель - Observer. 2016. № 6 (317).

[19] Иванов В.Г. Концепция государственной состоятельности: сравнительные межстрановые рейтинги против государственной легитимности // Вестник Российского университета дружбы народов. Серия: Международные отношения. 2015. Т. 15. № 3.

[20] Дуткевич П., Казаринова Д.Б. Конец эпохи глобализации: причины и последствия // Вестник Российского университета дружбы народов. Серия: Политология. 2017. Т. 19. № 1. C. 7-14.

[21] Сорокин А.Н. На периферии восточной политики ФРГ: Аденауэр и страны Восточной Европы // Омский научный вестник. 2015. № 4 (141).

[22] Уайm C. Европейский союз, Восточная Европа и «империализм ценностей»// Вестник МГИМО Университета. 2014. № 4 (37).

[23] Хорват Д. Аспекты модернизации политики регионального развития в Центральной и Восточной Европе в контексте изменений в Европейском союзе // Регион: экономика и социология. 2014. № 1 (81).

[24] Хотькова E.C. Эволюция отношений США со странами Центральной и Восточной Европы // Проблемы национальной стратегии. 2009. № 1.

[25] Глебов В.А., Амиантова И.С. Европейский мультикультурализм: миф или реальность? // Вопросы национальных и федеративных отношений. 2016. № 4 (35).

[26] Шумов B.B. Общественная и национальная безопасность: анализ, моделирование и верификация // Политика и общество. 2015. № 3.

[27] Szulc T. Unpleasant Truths about Eastern Europe // Foreign Policy. № 102 (Spring, 1996).

DOI: $10.22363 / 2313-1438-2017-19-3-230-238$

\title{
THE MILITARY AND POLITICAL INFLUENCE OF THE UNITED STATES AND WESTERN EUROPE IN THE EASTERN EUROPEAN REGION
}

\author{
M.Yu. Penkov \\ The Institute of International Relations and Social and Political Sciences \\ Moscow State Linguistic University \\ Ostozhenka, 38, 119034, Moscow, Russia
}

\begin{abstract}
The subject of the study is the military policy of the United States and Western European countries in the Eastern European region. The article shows the focus of the US and Western Europe to consolidate and expand its influence in the East European region and the establishment of the post-Soviet space "cordon sanitaire" around Russia. Particular attention is paid to the analysis of the West's desire to use the Eastern European countries to create a zone of instability in the countries bordering on Russia and Euro-Atlantic integration processes in Eastern Europe. The main conclusion of the study is that the United States and Western European countries are using all possible, including clearly contrary to international law, the methods (a good example is the Ukraine) to engage the countries of Eastern Europe and, in particular, the former Soviet republics into the orbit of its influence. At the same time for the sake of their own interests, they are ready to accept a purely political decision to integrate into Euro-Atlantic structures, even those countries that do not meet the criteria of the West.

Key words: foreign policy, trans-national policies, democratic institutions, the integration of Eastern European countries, foreign policy, European influence of the United States, the Eastern European region, coalition politics, European geopolitical architecture, world politics
\end{abstract}




\section{REFERENCES}

[1] Antologija. Rasshirenie Evrosojuza za schet stran Central'no-Vostochnoj i Jugo-Vostochnoj Evropy. Oshibki realizacii ili bankrotstvo koncepcii. RISI, 2014 (in Russ).

[2] Artemenko S.V., Fedorova I.L. Evropejskaja regional'naja geopolitika kak jelement razvitija transgranichnyh territorij. Problemy bezopasnosti rossijskogo obshhestva. 2014; 1 (in Russ).

[3] Bajrektorevich A. Vostochnaja Evropa - mir poslednih otstajushhih. Pravo i politika. 2015; 4 (in Russ).

[4] Gejti Ch. Shag nazad v Central'noj i Vostochnoj Evrope. The Quarterly Journal. 2007; Vol. VI; 3 (in Russ).

[5] Ginijatov F.M. Politicheskie i jekonomicheskie aspekty prisoedinenija stran Central'noj i Vostochnoj Evropy k Evropejskomu sojuzu. Vestnik jekonomiki, prava i sociologii. 2014; 2 (in Russ).

[6] Frolova O.A. Analiz vneshnepoliticheskih dokumentov administracii Dzh. Busha-mladshego i B. Obamy kak osnovopolagajushhih strategicheskih doktrin politiki SShA na mirovoj arene. Vestnik Rossijskogo universiteta druzhby narodov. Serija: Politologija. 2015; 4 (in Russ).

[7] Kalan D., Derlik M. «Hromye tigry» Vostochnoj Evropy: neortodoksal'naja jekonomicheskaja politika v Vengrii protiv mer zhestkoj jekonomii v Rumynii. Mir peremen. 2016; 1 (in Russ).

[8] Kobrinskaja I.Ja. Politika SShA v central'noj i vostochnoj Evrope. SShA—Kanada: jekonomika, politika, kul'tura. 2000; 2 (in Russ).

[9] Kukushkin Ju.A., Bogomolov A.V., Ushakov I.B. Matematicheskoe obespechenie ocenivanija sostojanija material'nyh system. Informacionnye tehnologii. 2004; 7 (prilozhenie).

[10] Latkina V.A. Vostochnyj vektor evropejskoj politiki sosedstva: lovushki evropeizacii. Vestnik MGIMO Universiteta. 2014; 6 (39) (in Russ).

[11] Maslov Ju.K. Rol' grazhdanskogo obshhestva v formirovanii novoj sistemy vlasti v stranah Central'noj i Vostochnoj Evropy. Naukovij visnik Odes'kogo nacional'nogo ekonomichnogo universitetu. 2014; 7 (215) (in Russ).

[12] Prijmachuk D.V. Central'naja Azija i Soedinennye Shtaty Ameriki: problemy i perspektivy. Mezhdunarodnye otnoshenija. 2017; 1 (in Russ).

[13] Orlik I.I. Differenciacija Central'no-Vostochnoj Evropy i otnoshenija s Rossiej. M.: Institut jekonomiki RAN, 2015 (in Russ).

[14] Orlik-Garlik I.I. Central'no-Vostochnaja Evropa v sovremennoj geopolitike. Mir peremen. 2015; 4 (in Russ).

[15] Amiantova I.S. Mezhdunarodnye sankcii kak sposob reshenija politicheskih problem. Voprosy nacional'nyh i federativnyh otnoshenij. 2017; 1 (36) (in Russ).

[16] Putincev I.S. Varianty raspredelenija polnomochij v stranah Central'no-Vostochnoj Evropy. Mezhdunarodnye processy. 2015; Vol. 41 (in Russ).

[17] Kurylev K.P., Naryshkin V.S., Ozinkovskaja E., Rahimov K.H. Evrazijskij jekonomicheskij sojuz vo vneshnepoliticheskoj strategii Rossii. Vestnik Rossijskogo universiteta druzhby narodov. Serija Mezhdunarodnye otnoshenija. 2016; Vol. 16; 1 (in Russ).

[18] Abashidze A.H., Il'jashevich M.V. O zashhite nacional'noj identichnosti v globalizirujushhemsja mire. Nauchno-analiticheskij zhurnal Obozrevatel' - Observer. 2016; 6 (317) (in Russ).

[19] Ivanov V.G. Koncepcija gosudarstvennoj sostojatel'nosti: sravnitel'nye mezhstranovye rejtingi protiv gosudarstvennoj legitimnosti. Vestnik Rossijskogo universiteta druzhby narodov. Serija Mezhdunarodnye otnoshenija. 2015; Vol. 15; 3 (in Russ).

[20] Dutkevich P., Kazarinova D.B. Konec jepohi globalizacii: prichiny i posledstvija. Vestnik Rossijskogo universiteta druzhby narodov. Serija: Politologija. 2017; Vol. 19; 1 (in Russ).

[21] Sorokin A.N. Na periferii vostochnoj politiki FRG: Adenaujer i strany Vostochnoj Evropy. Omskij nauchnyj vestnik. 2015; 4 (141) (in Russ).

[22] Uajt S. Evropejskij sojuz, Vostochnaja Evropa i «imperializm cennostej». Vestnik MGIMO Universiteta. 2014; 4 (37) (in Russ). 
[23] Horvat D. Aspekty modernizacii politiki regional'nogo razvitija v Central'noj i Vostochnoj Evrope v kontekste izmenenij v Evropejskom sojuze. Region: Jekonomika i Sociologija. 2014; 1 (81) (in Russ).

[24] Hot'kova E.S. Jevoljucija otnoshenij SShA so stranami Central'noj i Vostochnoj Evropy. Problemy nacional'noj strategii. 2009; 1 (in Russ).

[25] Glebov V.A., Amiantova I.S. Evropejskij mul'tikul'turalizm: mif ili real'nost'? Voprosy nacional'nyh i federativnyh otnoshenij. 2016; 4 (35) (in Russ).

[26] Shumov V.V. Obshhestvennaja i nacional'naja bezopasnost': analiz, modelirovanie i verifikacija. Politika i obshhestvo. 2015; 3 (in Russ).

[27] Szulc T. Unpleasant Truths about Eastern Europe. Foreign Policy. № 102 (Spring, 1996).

(C) Пеньков М.Ю., 2017

\section{Об авторе}

Пеньков Михаил Юрьевич - аспирант Института международных отношений и социальнополитических наук Московского государственного лингвистического университета (e-mail: gniiivm-p@ya.ru) 